\title{
Personalized proteomics: The next step
}

\section{Jennifer Brown* \\ University of Iowa Health Care, USA}

Personalized or precision medicine is a recent trend among clinicians nowadays, as it has become increasingly important to understand the genetic makeup of each individual patient and then offer a customized diagnosis. This would not only help in developing effective strategies for the treatment of the disease, but also promise to have fewer side effects to the patient (Figure 1) [1,2]. This will directly transform clinical practice by affecting critical elements of management and care. The factual scientific goal of tailored proteomics is to describe the information flow within the cell (intra- and extracellular signalling networks) and the organism. This information flow is facilitated through, and by, protein pathways and networks [3].

Personalized proteomics or proteomic profiling, is the next big step in the field of personalized medicine to comprehensively understand the pathomechanism of the disease. Tissue specific expression of proteins by a genome, and its systematic analysis needs proteomics based technologies, as DNA sequence data only delivers a static snapshot of the various ways in which the cell might use its proteins, however the life of the cell is a dynamic process and needs to be deciphered at a more complex level. Among the emerging tailored proteomics based technologies, the identification of novel reliable biomarkers remains one of the biggest challenge [4]. A biomarker can be as simple as a laboratory examination or as complex as a pattern of proteins, determined by mass spectrometry, matrix-assisted laser desorption and ionization with time-of-flight (MALDI-TOF), surfaceenhanced laser desorption and ionization with time-of-flight (SELDI-

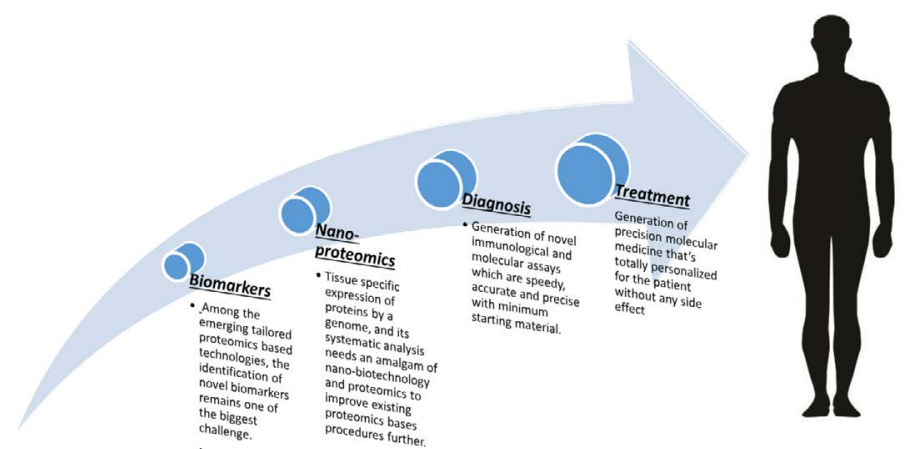

Figure 1. Personalized proteomics

The next step is to reveal novel biomarkers and merging nano-biotechnology with existing proteomics procedures to combat lethal diseases for comprehensive treatments with minimum side effects.

Copyright: $(2016$ Brown J. This is an open-access article distributed under the terms of the Creative Commons Attribution License, which permits unrestricted use, distribution, and reproduction in any medium, provided the original author and source are credited.
TOF), or two dimensional gel electrophoresis [5,6]. From a practical point of view, the biomarker would specifically and sensitively reflect a disease state and could be used for diagnosis as well as for disease monitoring during and following therapy.

Along with predictive biomarkers, protein chips can also be useful by generating miniaturized immunoassays that greatly improve the efficiency of diagnostic testing, by increasing the amount of information acquired with a single examination, and also decreases the cost by reducing reagent consumption. Similarly, nanoproteomics (an amalgam of nanobiotechnology and proteomics) will improve existing procedures further, including protein purification and automated identification, which currently yield unacceptably low recoveries with reduced sensitivity, decreased precision and speed and requiring more starting material [7]. Integrating such information with clinicopathological characteristics may lead to either detection of disease biomarkers useful to differentiate high-from low-risk patients, or to identification of new drug targets.

Newly emerging proteomic based studies just beginning from preand post-treatment tissues, will be the most rewarding. Last but not the least, the protein-targeted treatments will finally lead to develop precision molecular medicines for molecular targets expressed in malignancies and several autoimmune diseases.

\section{References}

1. Hays JL1, Kim G, Giuroiu I, Kohn EC (2010) Proteomics and ovarian cancer: integrating proteomics information into clinical care. J Proteomics 73: 1864-1872. [Crossref]

2. Lee JM1, Kohn EC (2010) Proteomics as a guiding tool for more effective personalized therapy. Ann Oncol 21 Suppl 7: vii205-210. [Crossref]

3. Jain KK1 (2016) Role of Proteomics in the Development of Personalized Medicine. $A d v$ Protein Chem Struct Biol 102: 41-52. [Crossref]

4. Hunter JM1, Paramithiotis E (2010) Protein biomarker quantification by mass spectrometry. Expert Opin Med Diagn 4: 11-20. [Crossref]

5. Xu W1, Hu Y, He X, Li J, Pan T, et al. (2015) Serum profiling by mass spectrometry combined with bioinformatics for the biomarkers discovery in diffuse large B-cell lymphoma. Tumour Biol 36: 2193-2199. [Crossref]

6. Simpkins F1, Czechowicz JA, Liotta L, Kohn EC (2005) SELDI-TOF mass spectrometry for cancer biomarker discovery and serum proteomic diagnostics. Pharmacogenomics 6 : 647-653. [Crossref]

7. Nicolini C1, Bragazzi N, Pechkova E (2012) Nanoproteomics enabling personalized nanomedicine. Adv Drug Deliv Rev 64: 1522-1531. [Crossref]
Correspondence to: Jennifer Brown, University of Iowa Health Care, USA, Tel: 319-335-3590; Fax: 319-335-3590; E-mail: jennifer-1-brown@uiowa.edu

Received: July 24, 2016; Accepted: August 23, 2016; Published: August 26, 2016 